\title{
A natureza política da gestão escolar e as disputas pelo poder na escola
}

ÂNGELO RICARDO DE SOUZA

Universidade Federal do Paraná

Considerando a forte marca política da ação dos dirigentes escolares e as tramas e redes de poder que se estabelecem nas relações cotidianas nas escolas (Souza, 2001; 2007; Gouveia; Souza, 2004), a gestão escolar pode ser compreendida como um processo político, de disputa de poder, explícita ou não, no qual as pessoas que agem na/ sobre a escola pautam-se predominantemente pelos seus próprios olhares e interesses acerca de todos os passos desse processo. Assim, visam a garantir que as suas formas de compreender a instituição e os seus objetivos prevaleçam sobre as dos demais sujeitos, a ponto de, na medida do possível, levá-los a agirem como elas pretendem.

Com isso, temos uma tentativa inicial de compreender a gestão escolar não como ela pode ou deve ser, mas como ela demonstra ser, considerando sobre o que ela recai e com quais objetivos opera.

A gestão é a execução da política, é por onde a política opera e o poder se realiza:

Não é possível separar a administração do governo, como é impossível separar a prática da teoria. A oposição tradicional entre direito constitucional e direito administrativo, ciência política e ciência administrativa, política e administração procura mostrar um mundo onde a execução está absolutamente separada da decisão, em nível dos que exercem o poder. Essa representação que busca neutralizar a administração é desmentida todos os dias na real relação de dominação. (Motta, 1986, p. 41)

Nesse sentido, a gestão é sempre um processo político, pois é uma "atividade-meio da política” (idem, p. 40), que lida diretamente com as relações de poder “à 
medida em que poder se delega. Isto significa que, intermediária ou não, ela age como sistema de poder" (idem, p. 49).

Isso quer dizer que não parece possível entender a ação administrativa isoladamente do poder que está sempre presente nela. Poder esse que se verifica nas relações escolares (pedagógicas, administrativas propriamente ditas, institucionais etc.) e pelo qual o controle sobre a instituição na busca de tais ou quais objetivos se faz (Teixeira, 1961, p. 85). Isto é, o controle sobre o poder escolar garante a definição dos ideais sobre os quais se edificarão os processos de gestão e, ao mesmo tempo, a própria gestão é um processo de busca, conquista, disputa e/ou diálogo e socialização do controle desse poder de decisão sobre os rumos que a instituição segue. A coordenação da política escolar é, em última análise, o objeto da gestão escolar.

Na medida em que a gestão escolar é uma espécie de braço executivo da política escolar e considerando que a política só existe porque se vislumbra o poder, cumpre perguntar: de que poder se trata? Inicialmente se relaciona a poder de mando, ou simplesmente dominação.

Weber identifica poder com política e vice-versa, pois para ele só há política quando se vislumbra o poder. Só há ação política quando há luta por poder, quando o poder está em disputa. Nem todo poder é dominação, ela "é um caso especial de poder" (Weber, 2004, p. 695). Poder implica imposição da vontade a outrem, dominação implica obediência (idem, p. 696). ${ }^{1}$ Logo, a dominação é o poder obedecido, incorporado.

A dominação, para Weber, é

[...] um estado de coisas pelo qual uma vontade manifesta ("mandato") do "dominador" ou dos "dominadores" influi sobre os atos de outros (do "dominado" ou "dominados"), de tal sorte que em um grau socialmente relevante estes atos têm lugar como se os dominados tivessem adotado por si mesmos e como máxima de sua ação o conteúdo do mandato ("obediência”). (idem, p. 699)

$\mathrm{Na}$ escola, o diretor, dirigente do processo político da gestão escolar e chefe de uma repartição pública, é uma autoridade dominadora. Nesse sentido, é um burocrata que tem funções a desempenhar. O lugar de diretor ${ }^{2}$ em uma escola não é feito por ele próprio (Pereira, 1976), mas para o seu desempenho utiliza centralmente a política e o conhecimento técnico. Os demais sujeitos na escola reconhecem essa autoridade dominadora e a obedecem. Assim, o poder desempenhado pela condução da gestão escolar é uma forma de dominação.

Então, governar uma escola implica dominar, uma vez que "toda dominação se manifesta e funciona em forma de governo. Todo regime de governo necessita do

1 Weber é um dos primeiros autores a associar ao poder a intencionalidade do dominador (Clegg, 1989, p. 73).

2 Não importa, neste texto, se esse lugar se trata de um cargo ou de uma função. 
domínio em alguma forma, pois para seu desempenho sempre se devem colocar em mãos de alguém poderes imperativos" (Weber, 2004, p. 701). Mesmo nos regimes democráticos, há, segundo Weber, um poder de mando e, portanto, uma forma de dominação:

O poder de mando pode ter uma modesta aparência e o chefe quase sempre pode ser considerado como um "servidor" dos dominados. Isto ocorre quase sempre no chamado governo diretamente democrático. Se chama (sic) democrático por duas razões que não coincidem necessariamente: 1) porque se baseia na suposição de que todo o mundo está em princípio igualmente qualificado para a direção de assuntos comuns; 2) porque reduz ao mínimo o alcance do poder de mando. (idem, p. 701)

Há, para Weber, distintas formas de dominação legítima: a) dominação racional-legal: na qual a obediência não se deve às pessoas, mas aos regulamentos, os quais, de sua parte, normatizam inclusive esse processo de obediência - "A burocracia constitui o tipo tecnicamente mais puro de dominação legal" (idem, p. 708); b) dominação tradicional: sustentada na crença ao poder decorrente da tradição do dominador, obedecendo-se a este por fidelidade pessoal do servidor à própria tradição; c) dominação carismática: baseada na devoção à pessoa do dominador e às suas capacidades (heroísmo, intelectualidade, oratória etc.), as quais são justamente responsáveis pela construção do seu carisma (idem, p. 707-711). Ao que parece, há na escola uma mistura entre as formas de dominação. Não há ali nenhuma forma pura, como de resto não há em qualquer esfera social (idem, p. 713).

A gestão da escola, pela sua natureza política, é dominação, pois "para a vida cotidiana dominação é primariamente administração" (idem, p. 175). Assim, para a condução cotidiana da escola, fundem-se a gestão e o poder. Em outras palavras, pode-se afirmar que, na escola, o domínio legítimo sobre as relações de poder é, de fato, o domínio sobre os processos de gestão escolar. A condução desta tarefa primeira dos dirigentes escolares não é por eles executada quando não detêm o domínio sobre as relações de poder.

\section{GESTÃO E A SOCIOLOGIA DA ESCOLA}

Mas, a escola é dominada de maneira racional-legal, tradicional ou carismática? Há pouco, comentou-se que não há na escola (ou nas outras instituições/organizações sociais) nenhum tipo puro de dominação e consequentemente nenhuma forma de administração e funcionamento puros.

Para parte das teorias organizacionais aplicadas à escola nos estudos clássicos da gestão escolar no Brasil, ${ }^{3}$ parece haver uma compreensão de que a gestão escolar é um

3 Leão (1953), Ribeiro (1952), Lourenço Filho (1976), dentre outros. 
conjunto de aspectos de natureza técnica, com campos de conhecimentos delimitados: a administração e a pedagogia. Esses pensadores compreendem, à luz da teoria clássica da administração ou das teorias das escolas que a substituíram (das teorias da burocracia), a gestão escolar como um fenômeno administrativo no qual os recursos são utilizados por meio das técnicas disponíveis para o alcance dos objetivos e fins da organização, ${ }^{4}$ portanto, sugerindo a ideia de uma forma/técnica ótima de se conduzir tal fenômeno.

Os estudos dos teóricos das organizações são voltados a identificar, analisar e compreender as formas pelas quais elas se constituem e são conduzidas no alcance de seus objetivos e, em particular, dedicam-se também a apresentar as formas pelas quais essas organizações podem equacionar os seus problemas e atingir seus fins, com a perspectiva de um olhar marcadamente normativo, em uma busca por projetar as melhores formas organizacionais em dado contexto e estrutura. ${ }^{5}$

Mais preocupados com a observação das formas utilizadas pelas organizações formais na sua estrutura e funcionamento, Blau e Scott (1962) percebem-nas constituídas deliberadamente para dados fins e para dar conta de algo que só pode ser feito por um grupo de pessoas. Nada nessas organizações é natural e os seus fins são explícitos. Para os autores, a complexidade da sociedade pode ter levado à crescente formalização das organizações e à criação de novas organizações formais. A formalização e formalidade dessas organizações não implicam que os sujeitos respondam a elas do jeito que se havia planejado/desejado. Ao contrário, as pessoas organizam-se, agrupam-se, dispõem-se favorável e contrariamente aos interesses oficiais das organizações. Elas compõem organizações dentro das organizações. São as organizações informais. Os hábitos, valores, crenças, representações, emergem dessas organizações informais, e esses elementos não coincidem, necessariamente, com os objetivos e estratégias das organizações formais nas quais existem.

Nas escolas muitas vezes parece haver um conjunto de elementos que dificulta o alcance dos seus objetivos formais. Esses elementos estão vinculados às relações que transcendem as de trabalho: os grupinhos de conversa entre professores e demais

4 O uso do termo "organização" nesse contexto não leva em consideração a importante discussão travada por Chauí (1999) acerca das diferenças conceituais entre organização e instituição, na qual a autora destaca que a escola (de qualquer nível) não é uma organização, mas sim uma instituição, uma vez que sustentadora da própria modernidade. $\mathrm{O}$ uso dessa expressão neste texto se deve ao fato de que, para os autores em questão, esse uso é preferencial, assim, ao reproduzir as suas discussões, prioriza-se este formato. De qualquer forma, há ainda controvérsia sobre os sentidos/significados daqueles termos e o seu uso no estudo sociológico da escola. Em especial, no uso do termo "organização", que remete tanto à ideia de organizar a ação da instituição como à ideia de instituição em si (registre-se aqui a importante discussão que Licínio Lima trava acerca desta questão).

5 "A teoria das organizações não tem se caracterizado apenas pelo determinismo tecnológico. Ela tem também, particularmente desde o crescimento do modelo dos sistemas abertos, se caracterizado pelo determinismo ambiental no qual a estrutura das organizações é vista como a resposta às pressões ambientais" (Clegg; Dunkerley, 1990, p. 5). 
para críticas ao diretor; os grupos de fumantes que se reúnem na cozinha ou no pátio durante/entre as aulas; as panelinhas do diretor, formadas por aqueles que the são mais simpáticos etc. A maioria dessas e outras formações espontâneas apresentam aspectos disfuncionais à organização racional da escola, uma vez que não são aproveitadas positivamente por ela (Pereira, 1976, p. 100). Esses grupos informais também operam nas relações de poder, sendo, por vezes, determinantes para a sua compreensão (Santos Guerra, 1994, p. 199-202; Candido, 1964). ${ }^{6}$ Mesmo porque parte das crises políticas e institucionais da escola é passível de ser explicada pela (falta de) relação entre a ação do diretor e os grupos informais, nos quais há costumes estamentais mais arraigados e práticas marcadamente patrimonialistas. Ou nos termos de Pereira (1976, p. 104):

Uma das manifestações do colapso da administração da escola está na existência de grupos espontâneos formados pelos membros adultos da escola, cujas reuniões e atividades implicam desvios das obrigações profissionais e criam situações de conflito entre os subordinados e o diretor, que não consegue controlá-los.

Blau e Scott observam que quanto mais formal é uma organização, mais engendra organizações informais, como reação e/ou mecanismo de defesa dos sujeitos que nela atuam. Essas organizações informais são criadas para a solução dos problemas mais cotidianos das pessoas e para facilitar o convívio na rotina de trabalho, levando mesmo à formalização de algumas dessas organizações, quando elas entram em acordo com os interesses de quem detém o poder na organização formal e quando, certamente, interessa aos seus administradores. Há que se ter em mente que não há organizações informais sem organizações formais, e estas sempre terão dentro de si algum tipo de organização informal, como alerta Abrahamsson (1993, p. xvii): "afirmar que os processos informais constituem a vida real de uma organização é apenas tão inútil quanto dizer que a organização formal é o único conteúdo significativo de estudo". A compreensão sobre os processos de gestão dessas organizações formais somente se aproxima do que de fato ali acontece acerca das relações de poder quando os elementos atinentes às organizações informais são reconhecidos.

Mas, seja pela sua crescente complexidade, seja pela normatização das organizações informais, a também crescente formalização das organizações tem implicado em maior controle e dominação sobre as pessoas e sobre a produção, seja na fábrica, seja na escola, seja nas outras organizações. A escola é uma organização formal que foi consti-

6 "A estrutura total de uma escola é algo mais amplo, compreendendo não apenas as relações ordenadas conscientemente mas, ainda, todas as que derivam da sua existência enquanto grupo social. [...] A escola possui vida social interna mais complexa do que poderia sugerir a observação desprevenida. [...] Considerar apenas a vida consciente e racionalizada do grupo deixa de lado a sua vida profunda e espontânea, fruto da integração dos seus membros e que nem sempre encontra modos de exprimir-se pelas normas racionalmente previstas" (Candido, 1964, p. 107-8). 
tuída para atender a uma dada perspectiva de formação dos cidadãos, controlando-os e disciplinando-os para esse fim. Em uma frase, organizações são sempre uma forma de controle e dominação e a divisão do trabalho está quase sempre presente nelas (Etzioni, 1994), com os característicos métodos de controle da produção, mesmo que os mecanismos mais cotidianos de ruptura com a formalidade organizacional também se façam presentes.

A gestão escolar conceituada e organizada nos limites das teorias da burocracia ${ }^{7}$ encontra eco com esses aspectos mencionados. Repousa no princípio de que a escola deve se pautar por regras impessoais, gerais, com condutas e comportamentos altamente organizados e rotinizados, sustentando-se em uma divisão hierárquica do trabalho e dos poderes de mando, na qual os papéis de todos os sujeitos estão definidos e esses sujeitos devem agir em conformidade com aquelas regras, estabelecidas pelos postos hierárquicos mais altos (Weber, 1978; 2004). A base do pensamento da gestão escolar burocrática está centrada na ideia de que há uma forma/técnica ideal (eficiente) de se realizar os seus objetivos (eficaz), em uma aparente mescla entre uma racionalidade econômica e técnica, ao mesmo tempo. Assim, tomando a burocracia como referência para a organização e gestão escolar, tem-se que entender que o conceito de gestão se articula com os poderes de mando e com a hierarquia, com o domínio dos saberes e técnicas que lhe seriam próprios mediata e imediatamente e com a definição, mais uma vez hierárquica, de regras. ${ }^{8}$

A escola, com as suas diferentes formas de organização e gestão, parece estar para além de uma organização estritamente burocrática. Ela está entre o caos ou o casuísmo e a extrema racionalidade ou organização burocrática, isto é, tem-se a escola como uma instituição que está organizada com base nesses dois amplos aspectos, que por vezes se apresentam como antagônicos, mas que por vezes também convivem no mesmo estabelecimento. Lima (2001) apresenta um modelo para o conhecimento das formas de organização escolar que considera os objetivos e os métodos empregados na

7 Refere-se a teorias da burocracia porque não há apenas uma teoria da burocracia. Todas elas emergem da leitura sociológica compreensiva de Max Weber sobre a dominação racional-legal, mas não é esse autor, em qualquer hipótese, um teórico da burocracia. Ele é o principal sociólogo da burocracia, uma vez que preocupado em compreendê-la: "Weber nunca foi um admirador da burocracia, ao contrário disto, ele temia o perigo que ela representava para a humanidade e, por isso, buscava encontrar salvaguardas contra o seu poder" (Pinto, 1994, p. 17).

8 Não há aqui a intenção de se construir mais um conceito de burocracia, nem de dar conta daqueles aspectos que são comuns a toda e qualquer definição que se tenha dela. Mesmo porque, parece sempre muito complexo abarcá-la completamente: "No folclore nórdico, um sujeito encontra um ser mítico denominado huldra, uma bonita e jovem mulher que o atrai para a floresta, e ele vai vagueando para se aproximar dela e então de repente ela desaparece dando-lhe a volta. Nas ciências sociais, o conceito de burocracia tem desempenhado um papel similar ao da huldra: fascinante e sedutor, mas que se esvai no momento quando o analista-observador acredita que está a capturar suas mais verdadeiras características" (Abrahamsson, 1993, p. 4). A intenção é a de destacar aspectos da gestão escolar quando pautada essencialmente pela burocracia. 
condução das ações e o explicita em uma matriz que se expressa por meio daquilo que o autor chama de "Modo de Funcionamento Díptico da Escola como Organização" e que contempla essas faces aparentemente tão diversas.

De um lado, a administração burocrática, como o tipo mais puro de dominação racional-legal, que é "a forma mais racional de se exercer uma dominação; e o é nos sentidos seguintes: em precisão, continuidade, disciplina, rigor e confiança [...]" (Weber, 2004, p. 178). Administração essa que domina as formas modernas de organização. ${ }^{9}$ De outro lado, a anarquia organizada, com uma definição um tanto ambígua dos objetivos e processos, formas pouco organizadas (ou ausentes) de planejamento, pouco consenso (Lima, 2001, p. 30 e 46), problemas com a fluidez das informações, articulação débil (Santos Guerra, 2000). São extremos que, mesmo contraditórios, se compõem. Lima, inclusive, sugere a hipótese de que a burocracia pode ser, ela mesma, responsável pelo surgimento/incremento de uma certa desconexão na organização (Lima, 2001, p. 47), ${ }^{10}$ o que pode, a nosso ver, revelar o lado anárquico da gestão escolar.

A leitura weberiana da burocracia afirma que ela é a forma mais acabada do domínio do conhecimento sobre uma organização. ${ }^{11} \mathrm{O}$ que quer dizer que o controle da burocracia é na verdade o maior poder que alguém pode ter sobre uma organização (Castro, 1998). ${ }^{12}$ Contudo, outros autores (Scheurich, 1995; Littrell; Foster, 1995) chamam a atenção para o mito da administração e do seu conhecimento teórico, que é valorizado com o crescimento da burocracia, a qual, por seu turno, aparentemente se autorreproduz, nem sempre em respeito aos objetivos definidos nas normas impessoais, mas na conquista e/ou manutenção do poder para dados estamentos/corporações de funcionários. Há inclusive autores (Crozier, 1981; Merton, 1970) que questionam se a burocracia é na verdade tão racional quanto Weber avaliava.

Esse crescimento da burocracia apresenta-se no discurso da ótima organização, que se sustenta basicamente em quatro pontos: a) a racionalidade dos meios, ou tecnocracia; b) uma hierarquia que dá base para uma lógica de autoridade e de tomada de decisões; c) a presença de uma tradição ou cerimonial predeterminado; d) os dirigentes ficam ocultos por trás das ações de direção (Chauí, 1997, p. 9). Esse discurso é levado a toda e qualquer organização ou instituição da sociedade, tornando as ações ideológicas

9 “Toda nossa vida cotidiana está tecida dentre deste marco [a burocracia]" (Weber, 2004, p. 178).

10 "[...] admito mesmo a hipótese de a própria ordem burocrática poder produzir um certo grau de desconexão entre orientações normativas distintas." (Lima, 2001, p. 47).

11 "Há que se escolher entre a burocratização e o diletantismo da administração; e o grande instrumento da superioridade da administração burocrática é este: o saber profissional especializado" (Weber, 2004, p. 178).

12 Apesar de que "em certos contextos, Weber enfatizou decisivamente a subordinação da burocracia (straffe Unterordnung) e sua capacidade de ser um instrumento obediente para qualquer possuidor de poder. Em outros contextos, entretanto, ele a viu como um poder soberano em si com seus próprios interesses pela preservação do sistema social” (Abrahamsson, 1993, p. 35). 
em ações impessoais, anônimas. Esse discurso tornou-se o discurso da burocracia, ou da cientificidade, ou ainda do conhecimento (idem, p. 11).

A face da burocracia, ${ }^{13}$ que no modelo de Lima expressa as formas mais racionais de organização e gestão, ${ }^{14}$ é identificada pelos objetivos da organização escolar, que são consensuais, as normas são abstratas e as estruturas são formais, o que constitui uma racionalidade instrumental/técnica da gestão escolar (Lima, 2001, p. 24). O modelo burocrático é o preferido nos estudos sobre a gestão escolar, mas alerta o autor para o fato de que utilizar a burocracia como roteiro para esta análise não é um procedimento dos mais fáceis, pois, a despeito da burocratização da administração escolar, as escolas não são organizações puramente burocráticas.

De outro lado, o autor apresenta a anarquia, cujas características são os objetivos pouco claros, os processos insuficientemente compreendidos e a participação não bem definida das pessoas (Lima, 2001, p. 30). Nesta outra face do modelo, situações cotidianamente vivenciadas nas escolas parecem ser melhor perceptíveis, como a ausência de intenção em certas ações da gestão escolar e que ocorrem simplesmente pela tradição da repetição ou pela ação burocratizada, mas deslocada do seu real objetivo que é melhorar as condições pedagógicas de funcionamento da escola. $\mathrm{Na}$ anarquia, a escola é tida como um sistema debilmente articulado, ou seja, "como uma organização em que muitos dos seus elementos são desligados, se encontram relativamente independentes, em torno de intenções e de acções, processos e tecnologias adoptados e resultados obtidos, administradores e professores, professores e professores, professores e alunos etc." (idem, p. 33). A anarquia organizada

[...] desafia o modelo bem instalado da burocracia racional, não por procurar sobrepor-se-lhe, mas por procurar competir com ele na análise de certos fenómenos e de certas componentes das organizações. Ao modelo sério, quase sagrado, da racionalidade tradicional, o modelo anárquico opõe a "loucura sensata". (idem, p. 35)

Mas, como ressaltado anteriormente, a organização e gestão escolar não podem ser analisadas apenas com base em um desses modelos, tendo em vista que a escola é uma instituição rígida, departamentalizada, especializada, com regras universais (idem, p.28), de um lado, mas também é debilmente articulada, com muitas normas informais, com um sistema de comunicação ineficiente, por outro lado. $\mathrm{O}$ autor luso nos chama a atenção para esse aspecto da necessidade de não nos limitarmos a analisar a gestão

13 A burocracia é uma face do modelo, enquanto a anarquia é a outra face extrema. Apesar de não ser essa a nomenclatura do autor, parece que se trata de um modelo no qual a organização e a gestão escolar podem ser analisadas olhando-se de um extremo a outro, em um continuum. Esse é o sentido que aqui se dá de face: uma expressão possível da escola.

14 A burocracia é o modelo mais racional, se weberianamente pensada: "A administração burocrática significa, fundamentalmente, o exercício da dominação baseado no saber" (Weber, 1978, p. 27). 
escolar apenas sob um modelo, ao afirmar que "uma sociologia das organizações não poderá quedar-se pelo estudo apenas da morfologia organizacional, das estruturas formais do poder, terá de considerar também a estrutura informal [...], a 'rede informal' das organizações" (idem, p. 28).

A principal contribuição do modelo de Lima está centrada menos em potencialmente permitir observar a escola pelo seu bom ou mau funcionamento, isto é, pelo grau de aproximação ou distanciamento que a gestão escolar tem da burocracia, ${ }^{15}$ mas pela possibilidade de explicar, dentre outros aspectos, as razões de as disputas na política escolar ocorrerem de forma pouco centradas no domínio do conhecimento técnico e os porquês das decisões coletivas serem pautadas por interesses por vezes concorrentes aos objetivos escolares. Ou seja, há um conjunto de motivações que leva as pessoas a se posicionarem das formas como o fazem que transcende os limites das explicações mais racionais ou pelo menos das explicações mais evidentes. E o conhecimento sobre essas razões é importante para o desvelamento das relações de poder no interior da escola.

Em suma, as pessoas, individual e coletivamente, agem politicamente na/sobre a escola com o intuito de conquistar e manter o poder de mando sobre as outras pessoas e grupos. A compreensão sobre as formas pelas quais elas procedem nessas ações, bem como sobre os modos de funcionamento da escola podem ser analisados dentre aquele espectro amplo delimitado no modelo de Licínio Lima, destacando-se que o condicionante político da gestão escolar sempre estará presente.

\section{GESTÃO E PODER SIMBÓLICO}

Mas, não se trata sempre de poder de mando. O poder em disputa na escola nem sempre é uma forma explícita de dominação legítima. Há outras faces do poder na escola que pautam as disputas, que precisam ser observadas. O poder simbólico é uma dessas faces. ${ }^{16}$ Face sempre presente, legítima, mas de percepção menos evidente, assim obscura, o poder simbólico é "esse poder invisível o qual só pode ser exercido com a cumplicidade daqueles que não querem saber que lhe estão sujeitos ou mesmo que o exercem" (Bourdieu, 2004, p.7-8). O poder que o coletivo de professores tem em relação ao discurso pedagógico para os familiares dos alunos é uma forma de poder simbólico. A presença do diretor, em si, na reunião do conselho de escola manifesta o poder simbólico. Isto é, esse tipo de poder é vivenciado cotidianamente nas escolas nas disputas por espaço, imposição de ideias e influência na definição dos rumos a serem perseguidos pela instituição.

O poder simbólico se expressa de diferentes formas, mas uma muito particular é através do gênero. $\mathrm{O}$ mundo masculinizado tende a compreender o poder concentrado nas mãos dos homens ou nas concepções masculinas como algo natural. Esta naturalização

15 Tomando como referência que as características típico-ideais da burocracia poderiam, em teoria, contribuir para o bom funcionamento da escola.

$16 \mathrm{O}$ que não quer dizer que o poder simbólico não possa ser compreendido como uma forma de dominação. 
do domínio masculino nas relações sociais parece se reproduzir também em um universo marcadamente feminino, a educação escolar. $E$ as razões que levam o homem a ocupar posições de mando nesse universo podem ser explicadas pelo papel que a sociedade imputa aos homens e às mulheres, ${ }^{17}$ aos símbolos que eles representam, aqueles como sujeitos que têm de controlar/dominar, essas como pessoas que têm de agir/operar. Apesar dos grandes avanços conquistados pelas lutas das mulheres, elas, em muitos casos, ainda

[...] não podem decidir sobre suas vidas, não se constituem enquanto sujeitos, não exercem o poder e, principalmente, não acumulam esse poder, mas o reproduzem, não para elas mesmas, mas para aqueles que de fato controlam o poder. As pequenas parcelas de poder ou os pequenos poderes que thes tocam e que thes permitem romper, em alguns momentos ou circunstâncias, a supremacia masculina, são poderes tremendamente desiguais. (Costa, 2006, p. 5)

A linguagem é uma das ferramentas para o poder simbólico. ${ }^{18} \mathrm{O}$ discurso competente ${ }^{19}$ é uma expressão da reprodução dessa forma de poder. A forma como as culturas dominantes estabelecem o domínio sobre as culturas dominadas também é uma manifestação do poder simbólico. ${ }^{20} \mathrm{Na}$ construção da cultura escolar, mesmo sendo um processo de embate e que se sintetiza em um consenso mais ou menos artificial, fabricado, há presença desse tipo de poder, uma vez que, à guisa de exemplo, quando as pessoas da escola estão debruçadas sobre a elaboração do seu projeto político-pedagógico, ainda que com toda a disposição de o fazer de uma forma dialogada entre os diferentes segmentos escolares, sempre há pesos e significados diferentes de acordo com quem está articulando quais argumentos. Isto é, dependendo de quem seja o propositor de algum argumento, o peso desse argumento modifica-se, pois a representação política, institucional, ou mesmo pessoal do propositor tem um significado importante para os demais sujeitos, por vezes ainda mais importante do que o significado do próprio argumento, pois "o que faz o poder das palavras e das palavras de ordem, poder de manter a ordem ou de a subverter, é a crença na legitimidade das palavras e daquele que as pronuncia, crença cuja produção não é da competência das palavras" (Bourdieu, 2004, p. 15).

17 Sobre esse aspecto, conferir Mia Hultin (2003).

18 "[...] a linguagem é a parte mais inatingível e a mais atuante da herança cultural, [...] e [...] a linguagem universitária é muito desigualmente distante da linguagem efetivamente falada pelas diferentes classes sociais, [logo] não se pode conceber educandos iguais em direitos e deveres frente à língua universitária e frente ao uso universitário da língua, sem se condenar a creditar ao dom um grande número de desigualdades que são, antes de tudo, desigualdades sociais" (Bourdieu, 1998, p. 56).

19 "O discurso competente é o discurso instituído. É aquele no qual a linguagem sofre uma restrição que poderia ser assim resumida: não é qualquer um que pode dizer a qualquer outro qualquer coisa em qualquer lugar e em qualquer circunstância” (Chauí, 1997, p. 7).

20 "a cultura que une [...] é também a cultura que separa [...] e que legitima as distinções compelindo todas as culturas (designadas como subculturas) a definirem-se pela sua distância em relação à cultura dominante" (Bourdieu, 2004, p. 11). 
O poder simbólico é importante na observação da gestão escolar, na medida em que a dominação explícita nem sempre explica as razões acerca das decisões e encaminhamentos, controles e avaliações escolares. A análise da gestão escolar burocrática pode auxiliar a explicar aquilo que é explícito, uma vez que "o modelo burocrático concentra-se quase exclusivamente no estudo das 'versões oficiais da realidade"' (Lima, 2001, p. 28). Mas a falta de controle pela maioria das pessoas sobre as ações políticas na escola, portanto sobre a gestão escolar, não pode ser explicada apenas pelo respeito à hierarquia e à ordem estabelecidas pela organização burocrática. É possível acrescentar que essa falta de controle também, em parte, não é devida à tradição ou à subsunção das pessoas à figura de líder(es) carismático(s). As pessoas também não controlam o domínio ao qual estão submetidas porque há ainda, na escola, poderes não legítimos, como todas as formas de submissão pela violência, pela coação, pelo assédio moral.

A falta de conhecimento da maioria das pessoas sobre os seus direitos e, mais importante, sobre suas próprias potencialidades no enfrentamento ao poder constituído, legítimo ou não, é um ponto importante a ser contemplado na análise do campo da política escolar. ${ }^{21}$

A gestão escolar, então, como vimos, está no campo ${ }^{22}$ da política. E este campo é o lugar em que se geram, na concorrência entre os agentes que nele se acham envolvidos, produtos políticos, problemas, programas, análises, comentários, conceitos, acontecimentos, entre os quais os cidadãos comuns, reduzidos ao estatuto de 'consumidores', devem escolher, com probabilidades de mal-entendido tanto maiores quanto mais afastados estão do lugar de produção. (Bourdieu, 2004, p. 164)

A política em questão é esta: um mercado no qual a liberdade máxima parece ser, muitas vezes, apenas a de escolha entre uma ou outra opção, mas costumeiramente não é um espaço de participação ${ }^{23}$ e construção coletiva. ${ }^{24} \mathrm{~A}$ escola reverbera e reproduz, nesse sentido, ao menos em parte, as formas pelas quais a política opera na sociedade. Assim, mesmo quando há procedimentos, em princípio, mais democráticos na organização e gestão da escola, como é o caso da eleição de diretores, pode-se verificar problemas comparativos aos existentes nos pleitos regulares ocorridos em toda a sociedade (eleições para os parlamentos ou para prefeito, governador ou presidente da República). As

21 Este é um tópico importante a ser mais bem investigado: os poderes não legítimos. Todavia, no âmbito deste estudo, essa não é uma temática central e, como tal, não é explorada.

22 "Campo" aqui tem o sentido dado por Pierre Bourdieu, de locus de disputas, que são travadas na definição e imposição de modelo e concepções.

23 Supondo a participação como algo importante na construção de uma política mais democrática. Todavia, a não participação, como ação política efetiva, também pode ser compreendida neste mesmo sentido, considerando dada conjuntura. Voltaremos a esse ponto mais adiante.

24 "[...] o mercado da política é, sem dúvida, um dos menos livres que existem" (Bourdieu, 2004, p. 166). 
motivações para que as pessoas na escola tomem tal ou qual posição não parecem ser muito distintas daquelas que as movem a se posicionarem (ou não) na sociedade política. De um lado, provocados por aquela transformação de cidadãos em consumidores da política (e de resto da própria cidadania) (Touraine, 1998), somos levados a definir nossas posições pelos padrões de consumo e pelas aspirações que o mercado (político) nos oferece; de outro, em contradição, somos provocados a imergir em uma espécie de "seita" do comunitarismo, através dos constantes apelos ecológicos, de manifestações culturais etc., mas que também não deixam de ter sua face de "quase mercado" (Maroy, 2006), próprias dos pequenos ajuntamentos de pessoas, a qual nos força a definirmos nossas posições com base em interesses locais e desconectados com as reflexões mais amplas (da cidade, do estado, do país, ou da educação pública):

O resultado principal dessas condutas é o de nos colocar diante de uma escolha impossível entre um liberalismo selvagem e um comunitarismo ou um republicanismo fechado e intolerante; isto sufoca as novas reivindicações ao thes recusar todo espaço intelectual e político. (Touraine, 1998, p. 60)

Mas, é necessário considerar que os interesses imediatos, econômicos ou com consequências econômicas, individuais ou coletivas, não são os únicos motores da política. As pessoas na política (ativa ou passivamente) não se movem pautando-se apenas nesses interesses imediatos, supostamente controláveis por aqueles que governam:

[...] isso seria ignorar a eficácia propriamente simbólica da representação e da crença mobilizadora que ela suscita pela força da objetivação, equivaleria ainda a esquecer o poder propriamente político de governo que, por muito dependente que seja das forças econômicas e sociais, pode garantir uma eficácia real sobre essas forças por meio da ação sobre os instrumentos de administração das coisas e das pessoas. (Bourdieu, 2004, p. 175)

Não se trata apenas, portanto, e para reforçar o conceito apresentado páginas atrás, seja para quem governa, seja para quem é governado, de interesses econômicos, mas também de poder (que inclui o poder sobre a esfera econômica). ${ }^{25}$ Essa dualidade de interesses: econômicos e sociais de uma parte, e de controle e manipulação (Bourdieu, 2004 , p. 175) de outra, constitui-se no eixo sobre o qual a disputa pelo poder age, vale dizer, são as razões da ação política.

O poder de definição do governante é sempre grande, pois aqueles que o seguem tendem a convergir suas ideias para as do seu líder, ou a refletirem a partir daquilo que o líder/governante pensa, ou ainda, ao menos, a considerarem aquilo que ele estabelece

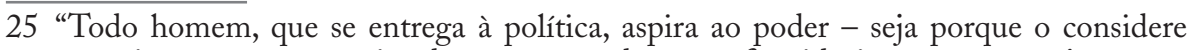
como instrumento a serviço da consecução de outros fins, ideais ou egoístas, seja porque deseje o poder 'pelo poder', para gozar do sentimento de prestígio que ele confere" (Weber, 1970, p. 57). 
como pauta. O controle e a manipulação política evidenciam-se em particular no estabelecimento daquilo que passa a ser considerado como assunto de interesse coletivo, vale dizer, quem estabelece o que todos podem discutir, via de regra, controla os modos como essa discussão vai se dar e, possivelmente, os resultados que dela emergirão. Esse é um marcante sentido de compreensão da gestão escolar como fenômeno político.

A disputa que ocorre na política é pelo direito de argumentar e (con)vencer os demais sujeitos de que as ideias que defende são as mais adequadas e, portanto, devem ser incorporadas como se elas fossem de todos. É a luta pelo monopólio da representação (idem, p. 185), na qual ao vencedor cabem as ideias dos representados, o seu direito de fala (e os seus silêncios) e a força que os representados têm como coletivo. Este monopólio pretende-se amplo mesmo nas situações em que o governante opera contra os interesses dos seus representados.

A apresentação dessas ideias do pretendente a governante é quase sempre definidora, pois se trata de demonstrar suas capacidades de agir em nome dos futuros governados: "Em política, 'dizer é fazer', quer dizer, fazer crer que se pode fazer o que se diz e, em particular, dar a conhecer e fazer reconhecer os princípios de di-visão do mundo social" (idem, 185).É, pois, antes de tudo, uma questão de confiança. Na política, o que se quer é a confiança dos governados. Por isso a política se sustenta no poder simbólico, uma vez que esse tipo de poder "existe porque aquele que lhe está sujeito crê que ele existe” (idem, p. 188). A ação política eficiente só é alcançada quando a confiança dos governados é depositada no governante. É curioso, todavia, que essa confiança não se sustenta, normalmente, nas capacidades propriamente políticas do pretenso governante, mas sim nas possíveis qualidades operacionais, ou técnicas, para a consecução dos interesses dos representados. Na gestão escolar, isso ainda parece mais evidente, pois não há um consenso aparente sobre a natureza política do dirigente escolar e, de qualquer forma, a confiança dos governados em uma "boa" gestão escolar parece residir justamente no domínio técnico-administrativo que os dirigentes escolares possam ter. ${ }^{26}$

Todavia, as lutas das ideias no processo político não se dão em uma arena fixa, com papéis definidos. Apesar de serem ideias que emergem de dadas concepções de mundo, na dinâmica disputa pelo poder as pessoas tomam posições mais pragmáticas. Os interesses imediatos, já mencionados, falam alto. Porém, mesmo contra eles, por vezes outros interesses são defendidos, antes de tudo com a necessidade de se manter no poder. Nesse sentido, concessões e acordos são firmados, estratégias e táticas são engendradas, com vistas exclusivamente à continuidade no controle e no poder, ou simplesmente com vistas a poder continuar existindo e agindo politicamente (idem, p. 196), seja na sociedade política, seja na escola.

26 Esta parece ser uma compreensão muito presente no eleitorado brasileiro, de forma geral, a julgar pela insistência de candidatos às mais diversas funções ao se apresentarem como tecnicamente habilitados para o exercício da função, fazendo o possível para não transparecerem uma imagem de políticos profissionais ou de pessoas que vivem da política, em termos weberianos (Weber, 1970, p. 64). 


\section{NOTAS FINAIS}

Este artigo evidenciou a face política da gestão escolar. Mais que isso, procurou demonstrar como essa face é definidora da natureza da gestão escolar, mesmo quando, de um lado, a burocracia é a principal ferramenta a seu serviço, pois a organização burocrática, que se repete e se justifica a si própria pela burocratização, mantém a importância, abrangência e domínio que the são reconhecidos pela concentração de determinados tipos de poder, discutidos ao longo deste trabalho.

De outro lado, as ações dos dirigentes escolares, por se tratarem de sujeitos à frente da coordenação política das escolas, são marcadamente políticas, ainda quando há ausência de objetivos e processos claros, transparentes e impessoais, isto é, quando o aparente caos domina a organização e o funcionamento das escolas, pois mesmo sabendo que aquelas ações não parecem pautadas por razões bem investigadas, há sempre elementos de disputa de poder por trás dos movimentos dos sujeitos políticos (Clegg, 1989; Weber, 1970; 2004).

Finalmente, este trabalho, ao evidenciar o reconhecimento da natureza política da gestão escolar, buscou auxiliar uma melhor compreensão acerca das ações e reações no fazer cotidiano dos dirigentes escolares e, nessa medida, potencializar a identificação de alternativas na condução da política educacional, particularmente no que concerne à democratização do direito à educação e a sua gestão. Uma vez conhecedores do possível grau de controle e de poder nas mãos dos dirigentes escolares, a sociedade civil pode cobrar e governos podem implementar mecanismos mais democráticos de escolha dos diretores escolares no Brasil.

\section{REFERÊNCIAS}

Abrahamsson, Bengt. The logic of organizations. London: Sage Publications, 1993.

Blau, Peter; Scott, W. Richard. Organizações formais. São Paulo: Atlas, 1962.

Bourdieu, Pierre. Escritos de educação. Organização de Maria Alice Nogueira e Afrânio Catani. Petrópolis: Vozes, 1998.

2004.

. Opoder simbólico. Tradução de Fernando Tomaz. Rio de Janeiro: Bertrand Brasil,

CANDIDO, Antonio. A estrutura da escola. In: Pereira, Luís; Foracchi, Marialice Mencarini (Org.). Educação e sociedade: leituras de sociologia da educação. 2. ed. São Paulo: Companhia Editora Nacional, 1964.

CASTRO, Magali. Um estudo das relações de poder na escola pública de ensino fundamental à luz de Weber e Bourdieu: do poder formal, impessoal e simbólico ao poder explícito. Revista da Faculdade de Educaşão, São Paulo: USP, v. 24, n. 1, 1998.

CHAứ, Marilena. Cultura e democracia: o discurso competente e outras falas. 7. ed. São Paulo: Cortez, 1997.

. A universidade operacional. Folha de S. Paulo, São Paulo, 09 maio 1999. p. 5-3.

CLEGG, Stewart. Frameworks of power. Londres: Sage Publications, 1989. 
ClegG, Stewart; DunKerLey, David. Organizations, class and control. Londres: Routledge, 1990.

Costa, Ana Alice. Gênero, poder empoderamento das mulheres. 2006. Disponível em: <http:// www.agende.org.br/docs/File/dados_pesquisas/feminismo/Empoderamento\%20-\%20 Ana\%20Alice.pdf $>$. Acesso em: out. 2006.

CROZIER, Michel. O fenômeno burocrático: ensaio sobre as tendências burocráticas dos sistemas de organização modernos e suas relações, na França, com o sistema social e cultural. Tradução de Juan A. Gili Sobrinho. Brasilia: Editora UnB, 1981.

EtZioni, Amitai. Análise comparativa de organizações complexas. São Paulo: Zahar, 1994.

GouveiA, Andréa; SouzA, Ângelo (Org.). Levantamento do custo-aluno em escolas públicas com condiçôes de qualidade no estado do Paraná. Relatório de Pesquisa. Curitiba: Setor de Educação/UFPR, 2004.

Hultin, Mia. Some take the glass escalator, some hit the glass ceiling? Career consequences of occupational sex segregation. Work and occupations, v. 30, n. 1, p. 30-61, 2003.

LEÃo, Antônio C. Introdução à administração escolar. 3. ed. São Paulo: Cia. Editora Nacional, 1953.

Lima, Licínio. A escola como organização educativa. São Paulo: Cortez, 2001.

LitTrelL, Janet; Foster, William. The myth of a knowledge base in administration. In: Donmoyer, R.; Imber, M.; Scheurich, J. J. (Ed.). The Knowledge Base in Educational Administration: Multiple Perspectives. Albany: State University of New York Press, 1995.

LouREnço Filho, Manoel B. Organização e administração escolar: curso básico. 7. ed. São Paulo: Melhoramentos; Brasília: INL, 1976.

Maroy, Christian. Convergences and hybridation of educational policies around "postbureaucratic models of regulation”. In: Congresso Mundial DE Sociologia, 16., 2006, Durban, África do Sul. Anais. África do Sul: ISA, 2006.

Merton, Robert K. Sociologia: teoria e estrutura. Tradução de Miguel Maillet. São Paulo: Mestre Joum, 1970.

MotтA, Fernando P. Organização E Poder. Empresa, Estado e Escola. São Paulo: Atlas, 1986. Pereira, Luís. A escola numa área metropolitana. São Paulo: Pioneira, 1976.

PINTO, José Marcelino R. Administração e liberdade: um estudo do conselho de escola à luz da ação comunicativa de Jürgen Habermas. 1994. Tese (Doutorado em Educação) UNICAMP, Campinas.

RibeIRo, José Querino. Ensaios de uma teoria da administração escolar. São Paulo: USP, 1952. Santos Guerra, Miguel A. Entre bastidores: el lado oculto de la organización escolar. Málaga: Aljibe, 1994.

. La escuela que aprende. Madri: Morata, 2000.

SCHEURICH, James J. The knowledge base in Educational Administration: postpositivist reflections. In: Donmoyer, Robert; Imber, Michael; Scheurich, James J. (Ed.). The knowledge base in educational administration: Multiple Perspectives. Albany: State University of New York Press, 1995. 
SouZA, Ângelo R. A escola por dentro e por fora: a cultura da escola e a descentralização financeira. Revista Ibero-americana de Educaşão, 2001. Disponível em: <http://www.campusoei.org/revista/fin_edu3.htm>. Acesso em: nov. 2006.

. Perfil da Gestão no Brasil. 2007. Tese (Doutorado em Educação: História, Política, Sociedade) - PUC-SP, São Paulo.

TeIXeIrA, Anísio. Que é administração escolar? Revista Brasileira de Estudos Pedagógicos, Rio de Janeiro, Brasília: INEP, v. 36, n. 84, p. 84-89, 1961.

Touraine, Alain. Igualdade e diversidade: o sujeito democrático. Tradução de Modesto Florenzano. Bauru: EDUSC, 1998.

Weber, Max. Ciência e Política: duas vocações. São Paulo: Cultrix, 1970.

. Os fundamentos da organização burocrática: uma construção do tipo ideal. In:

CAMPOS, Edmundo. Sociologia da burocracia. Rio de Janeiro: Zahar, 1978. .Economia y sociedad: esbozo de sociologia comprensiva. Tradução de José Medina

Echavarría, Juan Roura Parella, Eugenio Ímaz, Eduardo Garcia Máynez e José Ferrater Mora. México: FCE, 2004.

\section{SOBRE O AUTOR}

Ângelo Ricardo de Souza é doutor em educação pela Pontifícia Universidade Católica de São Paulo (PUC-SP). Professor adjunto da Universidade Federal do Paraná (UFPR).

E-mail: angelo@ufpr.br

Recebido em outubro de 2010 Aprovado em julbo de 2011 


\section{ÂNGELO RICARDO DE SOUZA}

\section{A natureza política da gestão escolar e as disputas pelo poder na escola}

Este artigo discute conceitualmente a gestão escolar, abordando aspectos da sua natureza e objeto, com o objetivo de contribuir com o debate teórico do campo. Utilizando contribuições de autores como Max Weber, Pierre Bourdieu e Licínio Lima, o trabalho aponta a face política da gestão escolar. O estudo conclui destacando que a presença de objetivos e processos institucionais claros e racionais na organização e gestão escolar ou, de outro lado, definições ambíguas desses processos, formas pouco organizadas (ou ausentes) de planejamento, pouco consenso e articulação débil não escondem a natureza política da gestão escolar, pois a ação dos sujeitos neste campo é marcada pela disputa pelo poder.

Palavras-chave: gestão escolar; política escolar; poder; burocracia.

\section{School administration political nature and the power struggle in school}

This article discusses conceptually the school administration, presenting some aspects of its nature and subject, with the objective to contribute with theorical debate in the field. Using contributions of Max Weber, Pierre Bourdieu and Licinio Lima, the work shows the political face of school administration. The study concludes highlighting that the existence of clear and rational objectives and institutional process or, on the other hand, ambiguous definition process, non-organized planning process, lower level of consensus and fragile articulation, don't hide the political nature of school administration, because the action of people in this field is defined by a fight for power.

Keywords: school administration; school politics; power; bureaucracy.

\section{La naturaleza política de la gestión escolar y la lucha por el poder en la escuela}

Este artículo discute conceptualmente la gestión de la escuela, acercando a aspectos de su naturaleza y objeto, con el objetivo para contribuir con la discusión teórica del campo. Usando 
contribuciones de autores como Max Weber, Pierre Bourdieu y Licinio Lima, el trabajo señala la expresión politica referente a gestión de la escuela. El estudio concluye destacando que la presencia clara y racional de objetivos y de procesos institucionales en la organización y gestión de la escuela o, de otro lado, a ambiguas definiciones de estos procesos, formas poco organizada $(0$ ausentes) del planeamiento, poco consenso y articulación débil no oculta la naturaleza politica de la gestión de la escuela, por lo tanto la acción de los ciudadanos en este campo es marcada por el conflicto con arreglo al poder.

Palabras clave: gestión de la escuela; política en la escuela; poder; burocracia. 